NASA/CR-2002-211948

ICASE Report No. 2002-39

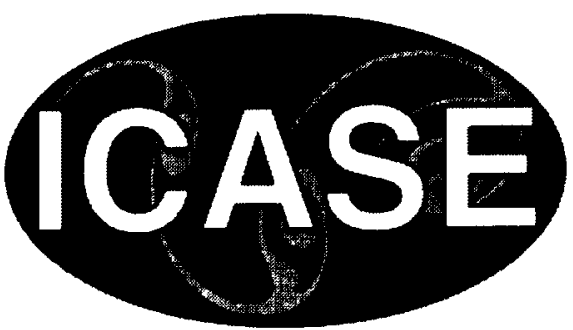

\title{
In Situ Poling and Imidization of Amorphous Piezoelectric Polyimides
}

Cheol Park, Zoubeida Ounaies, and Kristopher E. Wise ICASE, Hampton, Virginia

Joycelyn S. Harrison

NASA Langley Research Center, Hampton, Virginia

October 2002 


\section{The NASA STI Program Office ... in Profile}

Since its founding, NASA has been dedicated to the advancement of aeronautics and space science. The NASA Scientific and Technical Information (STI) Program Office plays a key part in helping NASA maintain this important role.

The NASA STI Program Office is operated by Langley Research Center, the lead center for NASA's scientific and technical information. The NASA STI Program Office provides access to the NASA STI Database, the largest collection of aeronautical and space science STI in the world. The Program Office is also NASA's institutional mechanism for disseminating the results of its research and development activities. These results are published by NASA in the NASA STI Report Series, which includes the following report types:

- TECHNICAL PUBLICATION. Reports of completed research or a major significant phase of research that present the results of NASA programs and include extensive data or theoretical analysis. Includes compilations of significant scientific and technical data and information deemed to be of continuing reference value. NASA's counterpart of peer-reviewed formal professional papers, but having less stringent limitations on manuscript length and extent of graphic presentations.

- TECHNICAL MEMORANDUM. Scientific and technical findings that are preliminary or of specialized interest, e.g., quick release reports, working papers, and bibliographies that contain minimal annotation. Does not contain extensive analysis.

- CONTRACTOR REPORT. Scientific and technical findings by NASA-sponsored contractors and grantees.
- CONFERENCE PUBLICATIONS. Collected papers from scientific and technical conferences, symposia, seminars, or other meetings sponsored or cosponsored by NASA.

- SPECIAL PUBLICATION. Scientific, technical, or historical information from NASA programs, projects, and missions, often concerned with subjects having substantial public interest.

- TECHNICAL TRANSLATION. Englishlanguage translations of foreign scientific and technical material pertinent to NASA's mission.

Specialized services that complement the STI Program Office's diverse offerings include creating custom thesauri, building customized data bases, organizing and publishing research results ... even providing videos.

For more information about the NASA STI Program Office, see the following:

- Access the NASA STI Program Home Page at http://www.sti.nasa.gov

- Email your question via the Internet to help@sti.nasa.gov

- Fax your question to the NASA STI Help Desk at (301) 621-0134

- Telephone the NASA STI Help Desk at (301) 621-0390

- Write to: NASA STI Help Desk NASA Center for AeroSpace Information 7121 Standard Drive Hanover, MD 21076-1320 
NASA/CR-2002-211948

ICASE Report No. 2002-39

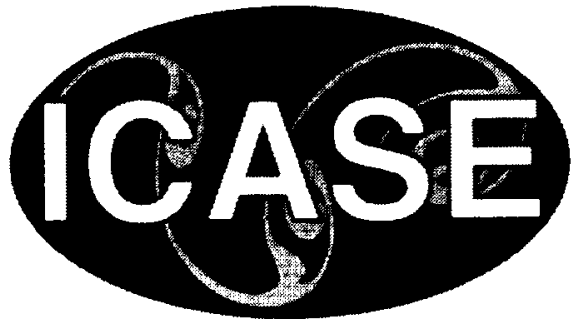

\section{In Situ Poling and Imidization of Amorphous Piezoelectric Polyimides}

Cheol Park, Zoubeida Ounaies, and Kristopher E. Wise ICASE, Hampton, Virginia

Joycelyn S. Harrison

NASA Langley Research Center, Hampton, Virginia

ICASE

NASA Langley Research Center

Hampton, Virginia

Operated by Universities Space Research Association 
Available from the following:

NASA Center for AeroSpace Information (CASI)

7121 Standard Drive

Hanover, MD 21076-1320

(301) 621-0390

National Technical Information Service (NTIS)

5285 Port Royal Road

Springfield, VA 22161-2171

(703) 487-4650 


\title{
IN SITU POLING AND IMIDIZATION OF AMORPHOUS PIEZOELECTRIC POLYIMIDES
}

\author{
CHEOL PARK ${ }^{1}$, ZOUBEIDA OUNAIES', KRISTOPHER E. WISE ${ }^{1}$, AND JOYCELYN S. HARRISON $^{2}$
}

\begin{abstract}
An amorphous piezoelectric polyimide containing polar functional groups has been developed using a combination of experimental and molecular modeling for potential use in high temperature applications. This amorphous polyimide, $(\beta-\mathrm{CN}) \mathrm{APB} / \mathrm{ODPA}$, has exhibited good thermal stability and piezoelectric response at temperatures up to $150^{\circ} \mathrm{C}$. Density functional calculations predicted that a partially cured amic acid (open imide ring) possesses a dipole moment four times larger than the fully imidized closed ring. In situ poling and imidization of the partially cured $(\beta-C N) A P B / O D P A$ was studied in an attempt to maximize the degree of dipolar orientation and the resultant piezoelectric response. A positive corona poling was used to minimize localized arcing during poling and to allow use of higher poling fields without dielectric breakdown. The dielectric relaxation strength, remanent polarization, and piezoelectric response were evaluated as a function of the poling profile. The partially cured, corona poled polymers exhibited higher dielectric relaxation strength $(\Delta \varepsilon)$, remanent polarization $\left(P_{r}\right)$ and piezoelectric strain coefficient $\left(d_{33}\right)$ than the fully cured, conventionally poled ones.
\end{abstract}

Keywords. in situ poling, amorphous polyimide, piezoelectricity, polarization, modeling

Subject classification. Structure and Materials

1. Introduction. Polymers containing dipolar functionalities have been studied as piezoelectric materials for many applications since the discovery of poly(vinylidene fluoride) (PVDF) [1], currently the only commercially available piezoelectric polymer. Majority of piezoelectric polymers are semicrystalline and usually need a favorable morphology to be efficiently polarized under an electric field, which often requires extensive mechanical stretching to attain a desirable conformation prior to poling. After poling, the aligned dipoles in these semicrystalline polymers are prone to mechanical relaxation at temperatures well below their Curie temperatures. Some amorphous polymers containing strong dipoles have also received great attention for their piezoelectric response because they usually do not require special treatment prior to polarization of the dipoles [2-7]. These amorphous piezoelectric polymers, however, usually exhibit much lower piezoelectric response than semicrystalline polymers. One exception, a vinylidene cyanide and vinyl acetate copolymer has been extensively studied because its piezoelectric response is comparable to PVDF [3-7]. A cooperative motion of four monomer units in a locally ordered structure has been proposed to explain the high dielectric relaxation strength [5]. Although an unusually high dielectric relaxation strength $\left(\Delta \varepsilon / \varepsilon_{0} \approx 125\right)$ was observed in this copolymer, this value was achieved only after drawing prior to poling. More extensive study has been hampered by difficulty in synthesis of the copolymer.

Recently, a series of amorphous piezoelectric polyimides containing polar functional groups have been developed at NASA Langley, based on molecular design and computational chemistry, for potential use in high temperature applications [8-10]. One of these, a polyimide containing a single cyano group, $(\beta-\mathrm{CN}) \mathrm{APB} / \mathrm{ODPA}$, retains more than $50 \%$ of its room temperature remanent polarization at $150^{\circ} \mathrm{C}$ for 500 hours ${ }^{11}$. The piezoelectric response of this polyimide is, however, an order of magnitude smaller than

\footnotetext{
1 ICASE, M/S 132C, NASA Langley Research Center, Hampton, VA 23681. This research was supported by the National Aeronautics and Space Administration under NASA Contract NAS1-97046 while the first three authors were in residence at ICASE, NASA Langley Research Center, Hampton. VA 23681.

${ }^{2}$ M/S 238, NASA Langley Research Center, Hampton, VA 23681.
} 
that of PVDF. This is in part arisen from the fact that the dipoles in the polymer do not align along the applied electric field efficiently because of limited chain mobility in the imidized closed ring structure. To increase the piezoelectric response of these polymers, two different approaches have been studied. The first approach uses "structural control" to increase the dipole concentration of the monomer unit by designing a new polymer [10]. The second approach uses "process control" to maximize the dipole orientation in a given structure by adjusting the poling process [11].

In the present study, the process control approach was employed to maximize the piezoelectric properties of the ( $\beta$-CN)APB/ODPA. Prediction of piezoelectric behavior in amorphous polymer systems is complicated by interplay of electronic and conformational effects [12]. We describe some recent results of an ongoing study aimed at better understanding this behavior using molecular modeling. These results indicate that a partially cured amic acid (open imide ring) exhibits higher net dipole moment than the fully imidized closed ring. In situ poling and imidization processing of a partially cured ( $\beta$ CN)APB/ODPA was employed to achieve efficient dipolar orientation. Positive corona poling was used to minimize localized arcing during poling and to enable use of a higher poling field without dielectric breakdown. The dielectric behavior, remanent polarization, and piezoelectric responses were assessed as a function of frequency and temperature.<smiles>N#Cc1c(Oc2cccc(N)c2)cccc1Oc1cccc(N)c1</smiles>

$(\beta-C N)$ APB<smiles>O=C1OC(=O)c2cc(Oc3ccc4c(c3)C(=O)OC4=O)ccc21</smiles>

RT, $\mathbf{N}_{2}$

DMAc<smiles>Cc1cccc(Oc2cccc(Oc3cccc(NC(=O)c4cc(Oc5ccc(C(=O)O)c(C(=O)N6CC7CCCC7C6)c5)ccc4C(=O)O)c3)c2C#N)c1</smiles>

Poly (amic acid<smiles>CC(O)CO</smiles><smiles>CCN1C(=O)c2ccc(Oc3ccc4c(c3)C(=O)N(c3cccc(Oc5cccc(Oc6cccc(C)c6)c5C)c3)C4=O)cc2C1=O</smiles>

FIGURE 1. Scheme of $(\beta C N) A P B / O D P A$ polymerization. 


\section{Experimental.}

2.1. Materials. The polyimide studied, $(\beta-C N) A P B / O D P A$, was prepared from 2,6-bis(3aminophenoxy) benzonitrile $((\beta-\mathrm{CN}) \mathrm{APB})$ and $4,4^{\prime}$ oxidiphthalic anhydride (ODPA) via a poly(amic acid) solution in N,N-dimethylacetamide. The scheme is shown in Figure 1. Details of the synthesis of ( $\beta$ CN)APB/ODPA have been described elsewhere [9]. The poly(amic acid) solution was cast onto a clean, dry glass plate using a doctor's blade in a low-humidity air chamber. The cast films were then dried in the chamber at room temperature overnight to form tack-free films. The dried films, approximately $30 \mu \mathrm{m}$ films in thickness, were cured under various cure cycles in an oven purged with nitrogen at a heating rate of $2^{\circ} \mathrm{C} / \mathrm{min}$ to produce samples with different degrees of imidization. The various cure cycles are summarized in Table 1. A silver layer, approximately $200 \mathrm{~nm}$ thick, was evaporated on both sides of the films for conventional poling and on only one side of the films for corona poling.
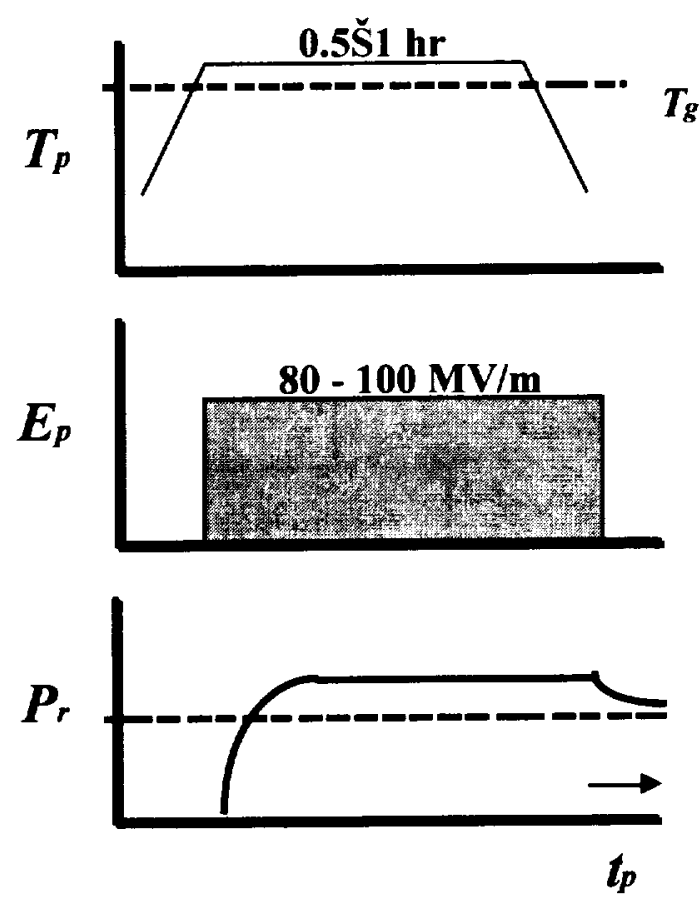

(a)
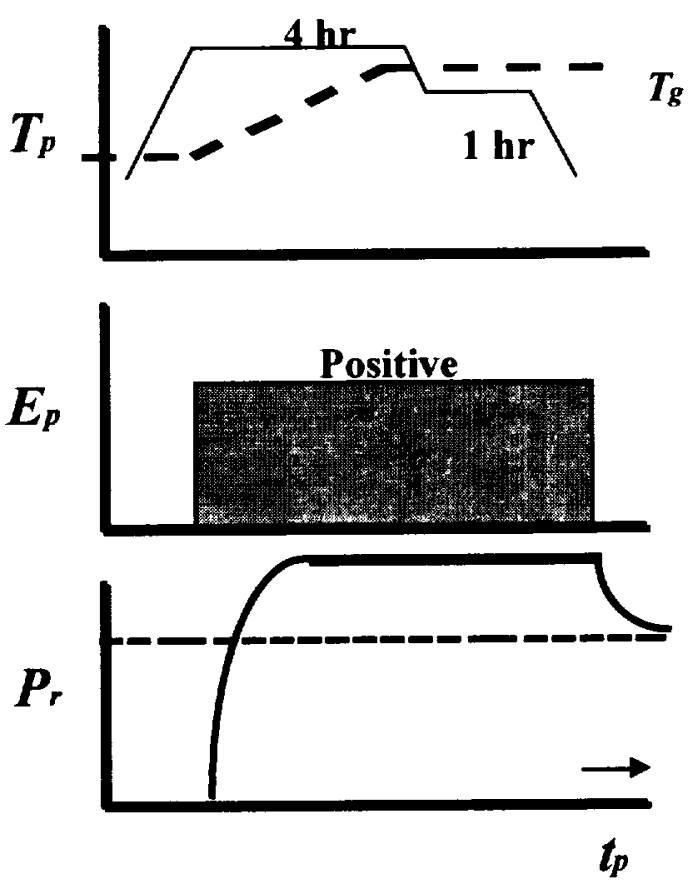

(b)

FIGURE 2. Poling profiles: (a) conventionally poled and fully cured, (b) corona poled and partially cured polyimide.

2.2. Poling procedure. Film specimens were poled using either a conventional or a positive corona poling procedure. For the conventional poling, each sample was polarized by application of a DC electric field $\left(E_{p}=80 \mathrm{MV} / \mathrm{m}\right)$ at an elevated temperature $\left(T_{p}=T_{g}+5^{\circ} \mathrm{C}\right)$ in a silicone oil bath for a selected poling time $\left(t_{p}\right)$. For corona poling, a DC voltage of $20 \mathrm{kV}$ was applied to generate a positive corona at the tip of a single tungsten wire for four hours at $223^{\circ} \mathrm{C}$ and one hour at $212^{\circ} \mathrm{C}$ using a mica hot plate. The distance between the corona tip and the specimen was $30 \mathrm{~mm}$. The corona poling setup was enclosed in a Plexiglass box, which was purged with argon gas during the poling process. For both poling processes, the dipoles were oriented with the applied field at a poling temperature $\left(T_{p}\right)$ above $T_{g}$, with subsequent cooling to below $T_{g}$ in the presence of the applied field. The poling profiles of the conventional and corona poling are shown in Figure 2 and the corona poling set-up is illustrated in Figure 3. The resultant remanent polarization $\left(P_{r}\right)$ is estimated from the following equation [13], 


$$
P_{r}=\varepsilon_{0} \Delta \varepsilon E_{p}
$$

where $\varepsilon_{0}$ is the permittivity of free space $(8.854 \mathrm{pF} / \mathrm{m}), \Delta \varepsilon$ is the dielectric relaxation strength, and $E_{p}$ is the poling field. The dielectric relaxation strength $(\Delta \varepsilon)$ is defined as the change in dielectric constant when a polymer transforms between unrelaxed (below $T_{g}$ ) and relaxed (above $T_{g}$ ) states. The piezoelectric response is directly proportional to the remanent polarization $\left(P_{r}\right)$.

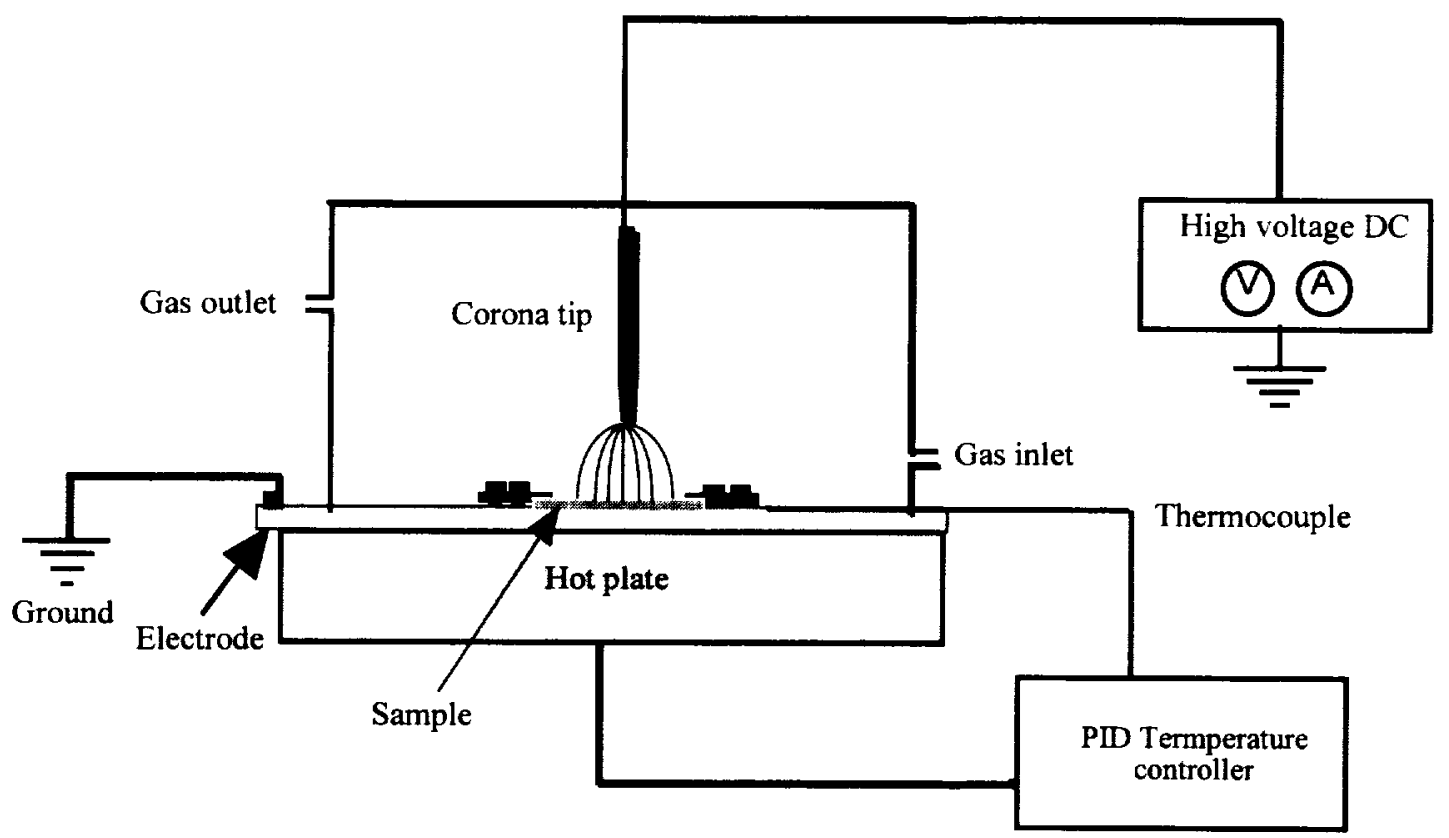

FIGURE 3. Schematic of corona poling set up.

\subsection{Characterization.}

2.3.1. Degree of imidization. The glass transition temperatures $\left(T_{g}\right)$ of the films were measured by differential scanning calorimetry with a Shimadzu DSC-50 at a heating rate of $10^{\circ} \mathrm{C} / \mathrm{min}$ in air. The $\mathrm{T}_{\mathrm{g}}$ was taken as the inflection point of the shift of the baseline of the DSC thermogram. The degree of imidization was determined by a Nicolet FTIR spectrometer in an ATR mode with a Nicolet Contin $\mu \mathrm{m}$ IR microscope. The absorption peak at $1780 \mathrm{~cm}^{-1}$ (symmetric carbonyl stretch) was used to determine the degree of imidization and that at $1380 \mathrm{~cm}^{-1}$ (ring breathing modes of the aromatic moieties) was used as an internal standard [14]. The results are presented in Table 1.

TABLE 1

Pracessing parameters and properties of partially-cured, corona poled ( $\beta C N) A P B / O D P A$.

\begin{tabular}{clccc}
\hline Sample & $\begin{array}{c}\text { Cure cycle }\left({ }^{\circ} \mathrm{C}\right) \\
1 \text { hour each, } \mathrm{N}_{2}\end{array}$ & $\begin{array}{c}\mathrm{T}_{\mathrm{g}} \text { before poling } \\
\left({ }^{\circ} \mathrm{C}\right), \text { DSC }\end{array}$ & $\begin{array}{c}\mathrm{A} 1780 \mathrm{~cm}^{-1} / \mathrm{A} 1380 \mathrm{~cm}^{-1} \\
\text { FTIR }\end{array}$ & $\begin{array}{c}P_{r} \\
\left(\mathrm{mC} / \mathrm{m}^{2}\right)\end{array}$ \\
\hline P100 & 50,100 & 97 & 0.18 & N/A \\
P150 & 50,150 & 142 & 0.69 & 38 \\
P200 & $50,150,200$ & 166 & 0.82 & 10 \\
P240 & $50,150,200,240$ & 218 & 1.00 & $14^{*}$ \\
\hline
\end{tabular}

${ }^{*} P_{r}$ was measured from conventionally poled $\mathrm{P} 240$. 
2.3.2. Dielectric measurement. The dielectric constant and loss of unpoled polyimide samples were evaluated as a function of temperature and frequency in a SUN System environmental oven with a Hewlett Packard 4192A Impedance Analyzer. The measurements were performed from room temperature to $300^{\circ} \mathrm{C}$ at a heating rate of $1^{\circ} \mathrm{C} / \mathrm{min}$ at $5,10,100$ and $1 \mathrm{k} \mathrm{Hz}$. These measurements yield the dielectric relaxation strength $\Delta \varepsilon$, which is a parameter of greatest interest in designing amorphous polymers with large piezoelectric activity [13].

2.3.3. Thermally stimulated current (TSC) measurement. After poling, the remanent polarization $\left(P_{r}\right)$ was measured as a function of temperature. As the sample was heated through its $\mathrm{T}_{\mathrm{g}}$ at a heating rate of $1.0^{\circ} \mathrm{C} / \mathrm{min}$, the depolarization current was measured using a Keithley 6517 electrometer. The remanent polarization $\left(P_{r}\right)$, equal to the charge per unit area, was obtained from the data by integrating the current with respect to time and plotting it as a function of temperature. This is given by,

$$
P_{r}=\frac{q}{A}=\frac{1}{A} \int i(t) d t
$$

where $q$ is the charge, $A$ is the electrode area, $i$ is the current, and $t$ is the time.

2.3.4. Piezoelectric strain coefficient measurement. Displacement measurements were performed using a non-contacting fiber optic sensor manufactured by Opto-Acoustic Sensors. Sinusoidal waveforms at a frequency of $1 \mathrm{~Hz}$ were used for all measurements. Multiple samples were measured at each condition, and the average displacement was recorded. Out-of-plane polymer motion is determined by monitoring the intensity of the light reflected from the polymer surface. As the surface of the piezoelectric films moves away from the sensor tip, the signal decreases, and as the surface moves closer to the sensor tip, the signal increases. The out-of-plane strain $\left(S_{33}\right)$ was measured in response to the applied electric field $(E)$, which is given by,

$$
S_{33}=\Delta t / t
$$

where, $t$ is the thickness of the polymer, and $\Delta t$ is the change in thickness. The piezoelectric strain coefficient, $d_{33}$, was obtained based on the following equation assuming a zero-stress boundary condition.

$$
S_{33}=d_{33} \cdot E
$$

\section{Results and Discussions}

3.1. Computational chemistry. In this section, we indirectly address the poling behavior and piezoelectric properties of ( $\beta-C N)$ APB/ODPA using a combination of molecular modeling techniques. We conceptually decompose the polarization response of a polymer into electronic, conformational, and orientational components. Electronic polarization refers to the transient reorganization of the electron density about an essentially fixed nuclear configuration. Conformational polarization describes the rotational response of small fragments or functional groups of the polymer that results from the coupling of 'local dipoles' to the external field. A local dipole is not a rigorously defined property of a molecule, but it is a useful mental model for visualizing the response of relatively rigid and electronically distinct fragments to an external field. We have chosen to use the term conformational polarization for this type of response to distinguish it from the more commonly used classifications of atomic polarization, which refers to small changes in bond distances or angles, and orientational polarization. Finally, orientational polarization describes the larger scale motions of segments of the polymer backbone. Obviously, this decomposition of the polarization response is artificial: electronic polarization is tightly coupled with 
conformational polarization, which is, in turn, tightly coupled with orientational polarization. Making this conceptual division is necessary, however, to bring studies of this kind within range of existing theoretical and simulation capabilities. The results presented in this section are restricted to conformational polarization, thus neglecting the electronic and orientational components for the time being.

As described in other parts of this paper, we are primarily interested in the relative response to poling and retention of polarization between the partially and fully cured forms of ( $\beta-C N) A P B / O D P A$. Inspection of Figure 4 reveals that the primary difference between the amic acid and the imide forms lies in the $(\beta-C N) A P B ~-~ O D P A ~ l i n k a g e$ region. The difference in conformational polarizability of the partially and fully cured forms must arise from the mobility in this region of the polymer (mostly from ODPA forms as that of $(\beta-C N) A P B$ is negligible). Another conceptual simplification is achieved by separating the mobility into a dipole field response term, which acts to orient the monomers in the direction of the field, and a dihedral energy barrier that tends to hold the monomers (and the intermonomer linkage) in its minimum energy configuration, which is generally not aligned with the field. In what follows, we examine some limiting cases to better understand the overall phenomenon.

Considering the ODPA monomer of the uncured polymer, it is evident that there are several fragments, each with a local dipole, which may respond relatively independently of the others to the external field. The orientation of the individual fragments will, in turn, collectively increase the total dipole moment of the ODPA monomer. This process will lead to improved monomer scale conformational polarizability, and even improved orientational polarizability. In contrast, the fully cured imide form of the polymer has no independently polarizable fragments. Therefore, any monomer level conformational
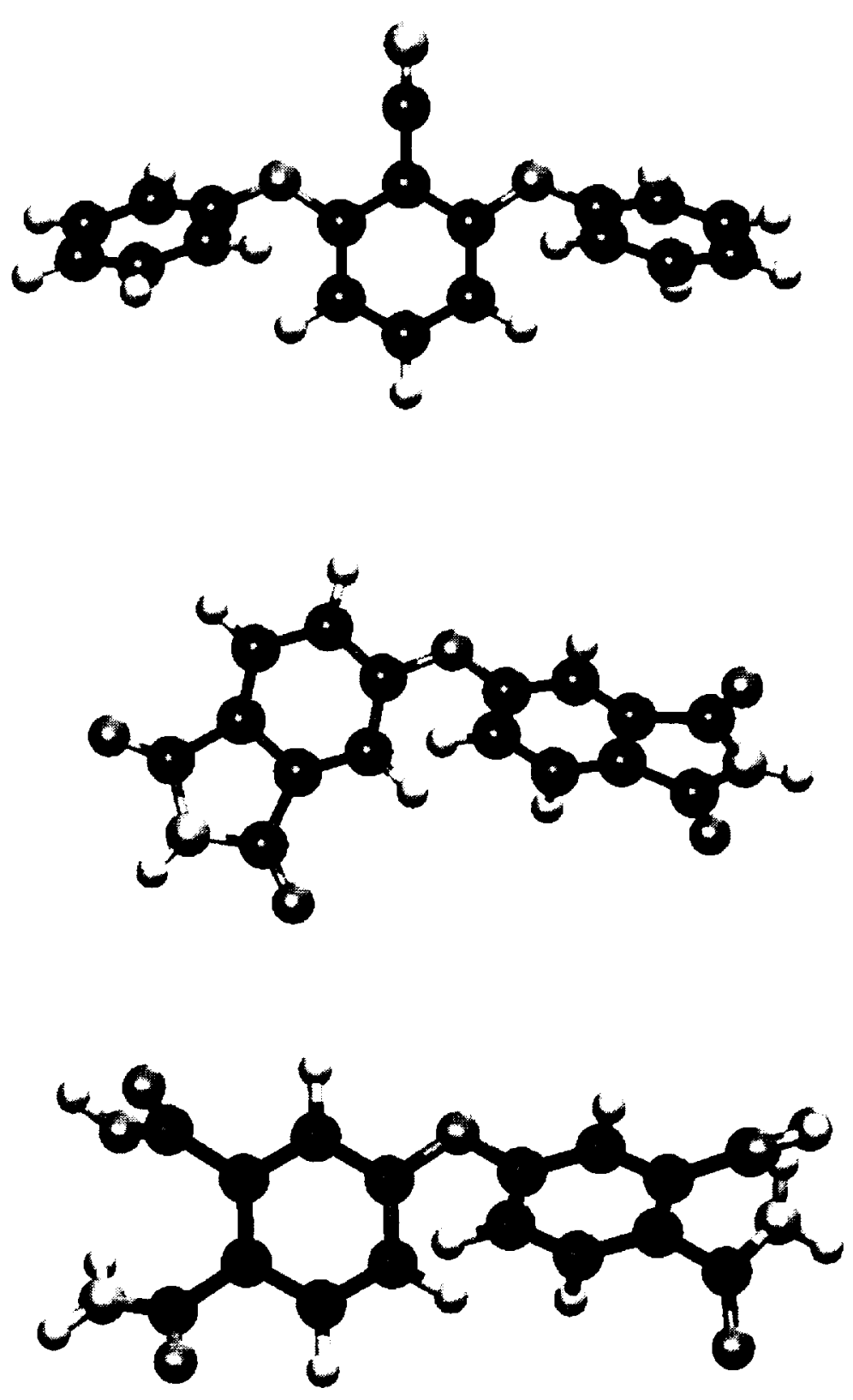

FIGURE 4. Molecular structures of monomers illustrating their conformations; (a) ( $\beta$-CN)APB, (b) cured, oriented ODPA (1.9D), (c) uncured oriented ODPA $18.8 D$ ). 
polarization or higher order orientational polarization must result from the intrinsic dipole of the rigid monomer.

To test the validity of this qualitative argument, we have carried out a series of calculations on the three limiting forms of the ODPA monomer: the uncured monomer in its field-free configuration, the uncured monomer after orienting the functional groups in an external field, and the cured, imide form of the monomer. Field effects on the imide form are ignored as they have no influence on its conformation polarizability. In the cases of the field-free uncured monomer and the cured monomer, geometry optimizations [15] were performed using the B3LYP density functional method [16] with a 6-31G* basis set [17]. Conformational poling of the uncured monomer was simulated by performing a molecular mechanics [18] minimization of the structure subject to a static external electric field of the same magnitude as used in the experiments $(80 \mathrm{MV} / \mathrm{m})$. Atomic charges [19] were derived from the quantum chemical calculation mentioned above for the field-free, uncured monomer. The use of charges from a field-free calculation neglects any internal electronic polarization effects, as mentioned above. Angular and dihedral force constants were taken from the literature [20], and all internal bond distances were held fixed [21]. After minimizing the geometry in this way, a single point B3LYP/6-31G* density functional calculation was performed on the structure to calculate the dipole moment. The dipole moments calculated using this procedure are summarized in Table 2.

TABLE 2

Dipole moments calculated of the cured and uncured, unoriented and uncured, oriented ODPA monomers.

\begin{tabular}{ccc}
\hline ODPA - Cured & ODPA - Uncured, Unoriented & ODPA - Uncured, Oriented \\
\hline $1.9 \mathrm{D}$ & $4.6 \mathrm{D}$ & $8.8 \mathrm{D}$ \\
\hline
\end{tabular}

The results in Table 2 clearly support the arguments made above. The uncured, field oriented monomer has a dipole moment almost twice as large as the uncured, unoriented monomer. Likewise, the uncured, unoriented monomer has a dipole moment more than double that of the cured, imide form of the polymer (either unoriented or field oriented). Comparing the uncured oriented monomer with the cured monomer reveals a factor of four difference in dipole moment. Since a statistical majority of the uncured ODPA monomers in the poling experiment will tend to be in an oriented conformation, the uncured amic acid form of the polymer will obviously be much more polarizable than the fully cured polyimide. This conclusion is in agreement with the experimental work reported in this paper.

3.2. Degree of imidization. A fully cured $(\beta-C N) A P B / O D P A$ sample was prepared from the dried tack-free polyamic acid film by thermal cure at $50,150,200$, and $240^{\circ} \mathrm{C}$ for an hour each under nitrogen atmosphere, which is denoted $\mathrm{P} 240$. Under this cure cycle, imidization of the amic acid appeared complete, and the glass transition temperature $\left(\mathrm{T}_{\mathrm{g}}\right)$ was $218^{\circ} \mathrm{C}$. For partially cured samples, the dried poly (amic acid) films were thermally imidized under nitrogen atmosphere at various cure cycles. The final cure temperatures of these samples were 100,150 , and $200^{\circ} \mathrm{C}$, which are denoted as P100, P150, and $\mathrm{P} 200$, respectively. For the partially cured samples, the degree of imidization was estimated by measuring $\mathrm{T}_{\mathrm{g}}$ and assessing FTIR spectra. The glass transition temperatures of the P100, P150, and P200 were 97 , 142 , and $179^{\circ} \mathrm{C}$, respectively. The ratio of the FTIR absorption peak at $1780 \mathrm{~cm}^{-1}$ (symmetric carbonyl stretch) versus that at $1380 \mathrm{~cm}^{-1}$ (ring breathing modes of the aromatic moieties) was also used to estimate the degree of imidization, assuming the ratio is 1.0 for the fully cured P240 [14]. The ratio increased with the final cure temperature as seen in Table 1 . For example, the partially cured P150 shows that $T_{\mathfrak{g}}$ was $142^{\circ} \mathrm{C}$ and the ratio of $A 1780 \mathrm{~cm}-1 / \mathrm{A} 1380 \mathrm{~cm}-1$ was 0.69 , which implies that significant amount of the amic acid remained unimidized after $150^{\circ} \mathrm{C}$ final cure. Therefore, higher mobility of the dipoles is 
expected for the polymers prepared at the lower final cure temperature. Table 1 summarizes the cure cycles, $T_{\mathrm{g}} \mathrm{s}$, and the FTIR absorption ratios.

The partially cured films were additionally imidized in situ during corona poling. To determine the poling profile, the imidization under the corona poling was monitored by measuring the $T_{\mathfrak{g}}$ as a function of the cure time on the mica hot plate. Imidization appeared to be complete within one and a half hours at $223^{\circ} \mathrm{C}$ on the hot plate. Therefore, the corona was applied on the partially cured film for at least two hours at $223^{\circ} \mathrm{C}\left(\mathrm{T}_{\mathrm{g}}+5^{\circ} \mathrm{C}\right)$ to achieve complete imidization.

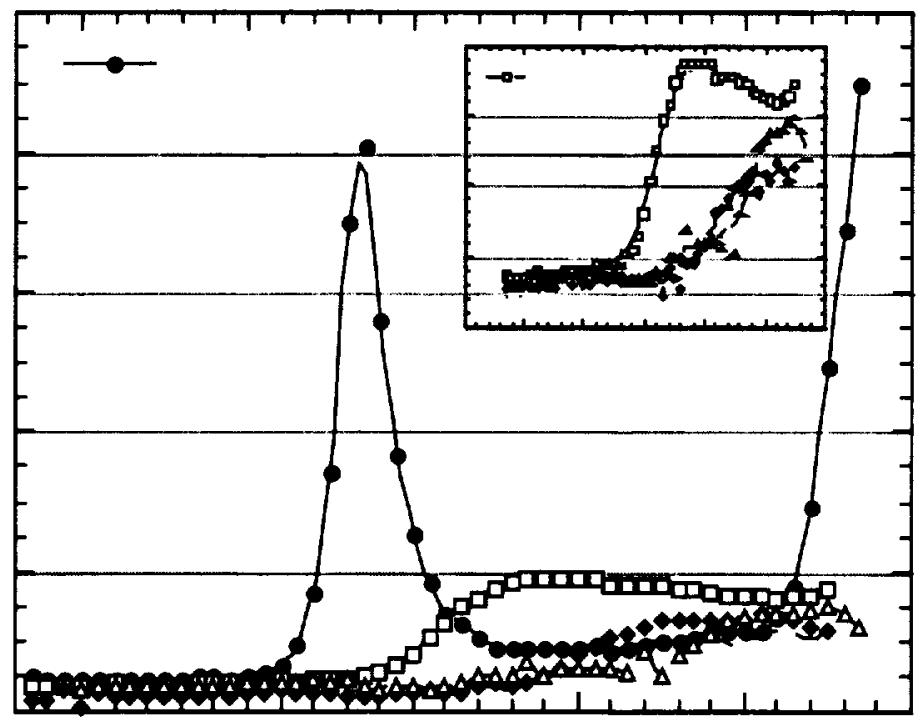

FIGURE 5. Dielectric behaviors of the films, P100, P150, P200, and P240, at 10Hz as a function of temperature.

3.3. Dielectric behavior. Computational modeling demonstrated that the uncured amic acid form of the polymer is much more polarizable than the fully cured polyimide. This higher polarizability can provide higher piezoelectric response. The piezoelectric response of a material can be predicted by the remanent polarization $\left(P_{r}\right)$, which in turn can be estimated from the dielectric relaxation strength $(\Delta \varepsilon$ according to Equation (1). The dielectric behavior of the polyimide films prepared at various cure cycles, $\mathrm{P} 100, \mathrm{P} 150, \mathrm{P} 200$, and P240, was studied as a function of temperature at various frequencies $(0.01,0.1,1$, and $10 \mathrm{kHz}$ ). The dielectric responses of the films, P100, P150, P200, and P240, at $10 \mathrm{~Hz}$ as a function of temperature are seen in Figure 5. A predominant peak appeared in the dielectric spectrum of P100 at around $110-160^{\circ} \mathrm{C}$. This peak is likely due to the release of remanent water gained from the solvent DMAc and/or generated from condensation reaction by imidization of the amic acid during heating. This large amount of water evaporation often caused excessive premature local dielectric breakdown during the in situ corona poling, and thus P100 was excluded from the poling study. For the specimens cured at temperatures higher than $100^{\circ} \mathrm{C}$, a noticeable dielectric relaxation appeared near $T_{g}$ for each spectrum. In addition, the onset temperature of the relaxation increased with the final cure temperature. The dielectric relaxation strength $(\Delta \varepsilon)$ increased with decreasing final cure temperature, as shown in the inset of Figure 5. This occurs mainly because the dipoles in the polymer chain cured at the lower temperature have higher mobility due to the more flexible amic acid ODPA (open ring). The lower $T_{g}$ value and the higher 
amount of the unimidized amic acids in the FTIR spectra suggested the higher mobility of the polymer chain cured at the lower temperature. In addition, the total dipole moment of the optimized amic acid exhibits a higher dipole moment (4.6 Debye) than the cured imide ring (1.9 Debye) in the ODPA backbone, as shown by the ab initio computation. This might contribute to the increase of the $\Delta \varepsilon$ as well.

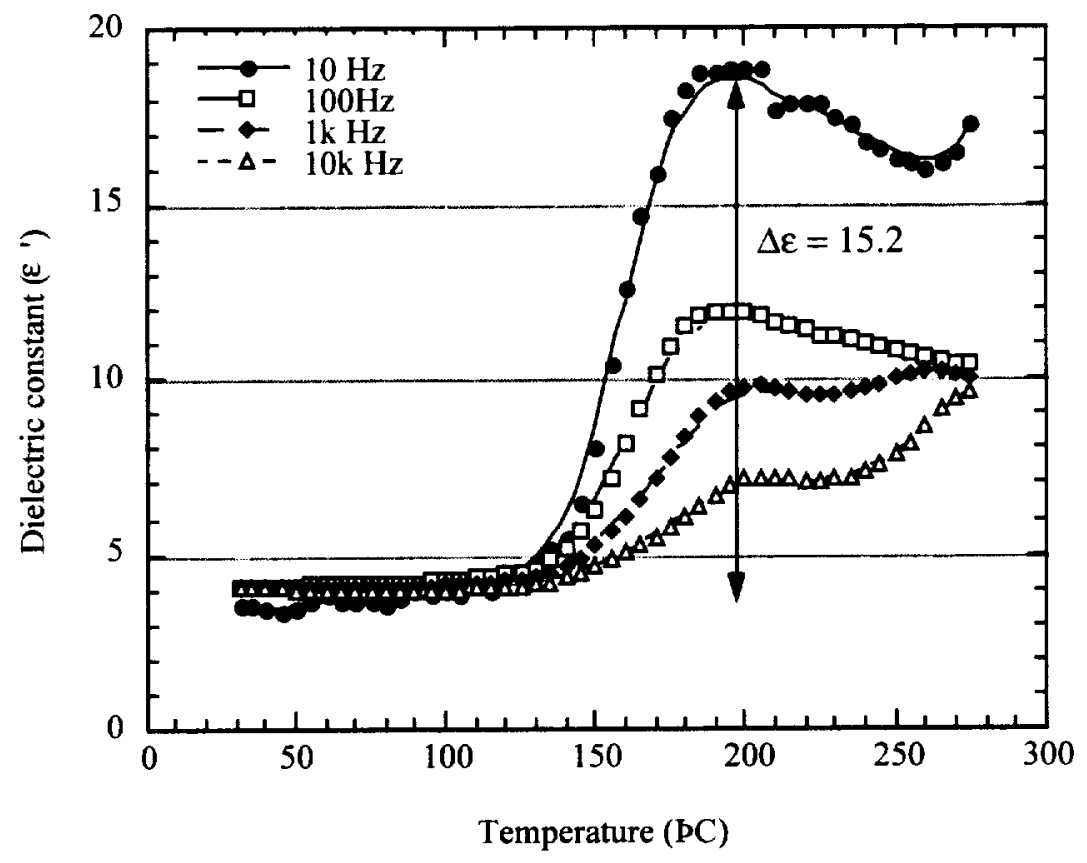

FIGURE 6. Frequency dependence of dielectric behavior for P150 as a function of temperature.

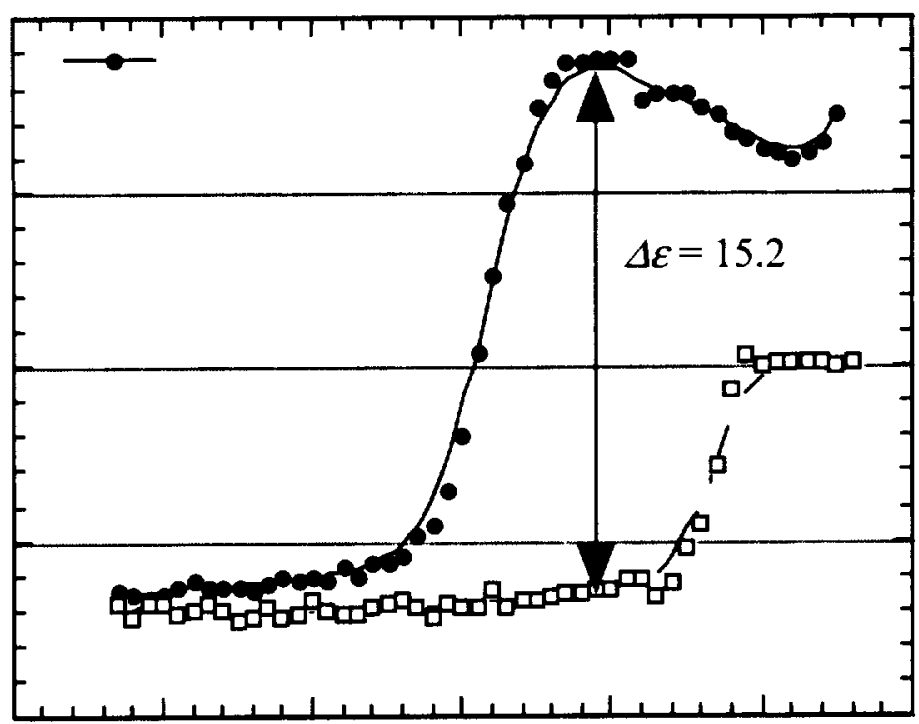

FIGURE 7. Dielectric constant of P150: first and second runs at $10 \mathrm{~Hz}$. 
Figure 6 shows the frequency dependence of the dielectric constant for P150 as a function of temperature. The dielectric relaxation strength $(\Delta \varepsilon)$ decreased with increasing frequency, while the onset temperature for the relaxation remained independent of frequency. This frequency sensitive dielectric behavior implies that $\Delta \varepsilon$ originated mostly from the orientational (and conformational) polarization caused by the highly polar components such as the nitrile group. $\Delta \varepsilon$ increased with decreasing frequency and reached a maximum of about 15.2 at $10 \mathrm{~Hz}$. It is expected that $\Delta \varepsilon$ will be even higher as the frequency approaches zero (DC), where the corona was applied for the actual poling procedure. The value of $\Delta \varepsilon$ at $1 \mathrm{~Hz}$ was estimated by extrapolating the values of the $\Delta \varepsilon$ as a function of frequency using a power law curve fit with a correlation coefficient of 0.97 . Based on the curve fit, the value of $\Delta \varepsilon$ at $1 \mathrm{~Hz}$ for the partially cured P150 was 22.4 and that of the fully cured P240 was 15.1 .

The second dielectric measurement of the partially cured P150 following the first run up to $280^{\circ} \mathrm{C}$ demonstrated a decrease in the $\Delta \varepsilon$ and higher onset temperature as shown in Figure 7. A similar result was observed for the second dielectric sweep of the fully cured P240. The magnitude of the $\Delta \varepsilon$ of the first run at $10 \mathrm{~Hz}$ was 15.2 and that of the second run was about 7.0 for P150. These observations imply that the imidization is completed during the first dielectric sweep and the sample behaves like a fully cured sample in the second run.

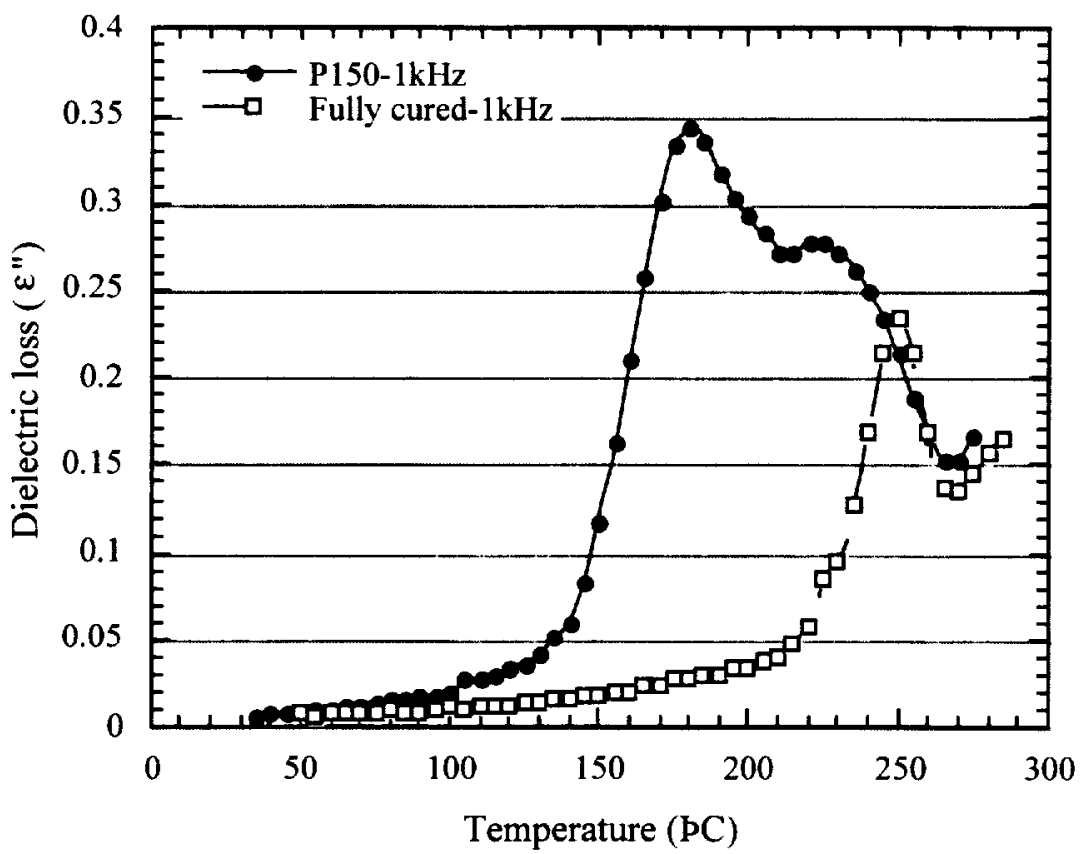

FIGURE 8. Dielectric loss of the partially (P150) and fully cured (P240) polvimides was also examined at $1 \mathrm{kHz}$

The dielectric loss of the partially cured (P150) and fully cured (P240) polyimides at $1 \mathrm{k} \mathrm{Hz}$ is shown in Figure 8. The dielectric loss spectrum of the P150 was more dissipative than that of the P240, which is probably associated with the higher mobility of the partially imidized polymer molecules of the P150 and the presence of remanent solvent. Moreover, P150 exhibited double relaxation peaks while P240 showed a single peak at a higher temperature. The two relaxation peaks of the partially cured P150 spectra probably resulted from the coexistence of both the open amic acid (lower peak) and imidized closed ring structure (higher peak). 
(a)
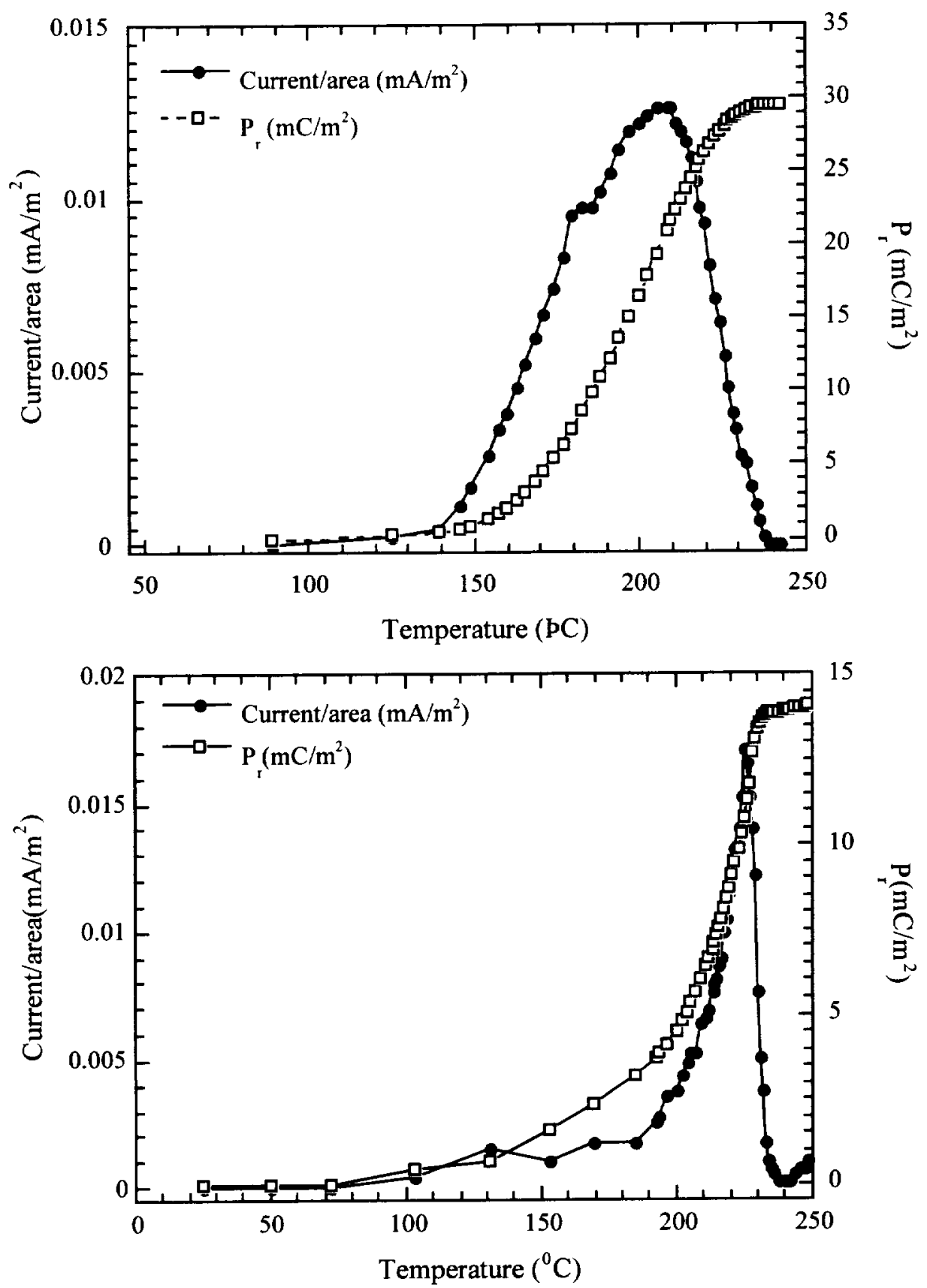

FIGURE 9. Typical TSC curves for conventionally poled P240 and corona poled P150 as a function of temperature.

The dipoles of the amic acids could align more efficiently at lower temperature in the presence of the corona field and some of these aligned dipoles will randomize as the temperature rises toward the final cure temperature due to thermal energy (Brownian motion) and progression of the imidization reaction. Nevertheless, some of the dipoles aligned close to the direction of the field may remain aligned to a certain extent along the corona field during the in situ poling and imidization procedure. Computational chemistry (section 3.2.) indicates that the total dipole moment of the uncured oriented amic acid form was approximately four times higher than that of the cured oriented one as seen in Table 
2. Consequently, these metastably aligned dipoles before imidization should increase the overall remanent polarization.

3.4. Thermally stimulated depolarization current (TSC). The amorphous polyimides were poled above the $T_{g}$ in a relaxed state to promote dipolar orientation, and then cooled slowly to room temperature while the applied electric field was being held to freeze the aligned dipoles. The degree of the alignment can be estimated by measuring the current released during heating of the polarized samples, which is called thermally stimulated depolarization current (TSC). Thermally stimulated depolarization current was measured for partially cured, corona poled polyimides and fully cured, conventionally poled polyimides. Figure 9 shows two typical TSC curves for conventionally poled P240 and corona poled P150 as a function of temperature. Depolarization of the conventionally poled P240 did not begin until the temperature reached about $20^{\circ} \mathrm{C}$ below $\mathrm{T}_{\mathrm{g}}$. At this temperature the depolarization current increased and then decreased rapidly, generating a sharp peak. In contrast, depolarization of the corona poled P150 began at a lower temperature (around $140^{\circ} \mathrm{C}$ ), and a broader peak was obtained. The depolarization onset temperature of the partially cured samples appeared to be correlated with the $T_{\mathrm{g}}\left(142^{\circ} \mathrm{C}\right.$ for $\left.\mathrm{P} 150\right)$ of the sample. The onset temperatures of $\mathrm{P} 150, \mathrm{P} 200, \mathrm{P} 240$ appeared at around $140^{\circ} \mathrm{C}, 180^{\circ} \mathrm{C}, 200^{\circ} \mathrm{C}$, respectively. Either a single peak with a shoulder or double peaks were seen in the TSC of the corona poled P150. The lower peak or shoulder appeared around $180-190^{\circ} \mathrm{C}$ while the higher one appeared at a temperature slightly lower than the depolarization peak of the conventionally poled P240. These TSC peaks correspond to the glass transition temperature of the polymer, and the $T_{g}$ of the corona poled P150 measured by DSC is shown in Table 1 . The area poled by corona appeared to have lower $T_{g}$ than the area where the corona was blocked during poling. This implies that the corona field might hinder the imidization of the amic acid since the rotational freedom of the molecule was decreased by the dipole alignment in the presence of the electric field. The broader depolarization peak of the P150 is attributable to a broader range of the $T_{\mathrm{g}}$ of the polymer as a result of the hindered imidization.

The value of remanent polarization $\left(P_{r}\right)$ is obtained by integrating the depolarization current with respect to time. The partially cured, corona poled polyimides exhibited higher $P_{r}$ values than the fully cured, conventionally poled ones. It appeared that $P_{r}$ was higher for polyimides cured with lower final cure temperatures, as seen in Table 1 . The highest value of $P_{r}$ about $38 \mathrm{mC} / \mathrm{m}^{2}$ was achieved when the partially cured P150 was poled and imidized in situ under the corona discharge. The P150 partially-cured, corona poled polyimide exhibited three times higher $P_{r}$ than the fully-cured, conventionally poled one. The $P_{r}$ of the corona poled polyimides, however, was not uniform, with values ranging from 10 to 50 $\mathrm{mC} / \mathrm{m}^{2}$, possibly because of nonuniform field generation by the single corona tip used for the poling. The highest $P_{r}$ value was obtained near the area below the tip, where more noticeable surface damage was observed.

The remanent polarization, $P_{r}$ can be also estimated according to Equation (1). Assuming the poling field was $100 \mathrm{MV} / \mathrm{m}$ with the extrapolated value of $\Delta \varepsilon$ at $1 \mathrm{~Hz}$, the values of $P_{r}$ are calculated to be 19.8 and $13.4 \mathrm{mC} / \mathrm{m}^{2}$ for the partially cured $\mathrm{P} 150$ and fully cured $\mathrm{P} 240$, respectively. The value for the $\mathrm{P} 150$, however, is in poor agreement with that measured experimentally $\left(38 \mathrm{mC} / \mathrm{m}^{2}\right.$, corona poled). The agreement for the $\mathrm{P} 240\left(14 \mathrm{mC} / \mathrm{m}^{2}\right.$ conventionally poled at $\left.80 \mathrm{MV} / \mathrm{m}\right)$ is much better. This is possibly due to underestimation of the applied field for the corona poling of the P150 and $\Delta \varepsilon$ for actual poling (DC). For the corona poling, much higher poling fields can be applied without causing a catastrophic dielectric breakdown of the film since the arcing can be localized and does not propagate transversely if the film has a high resistivity. 


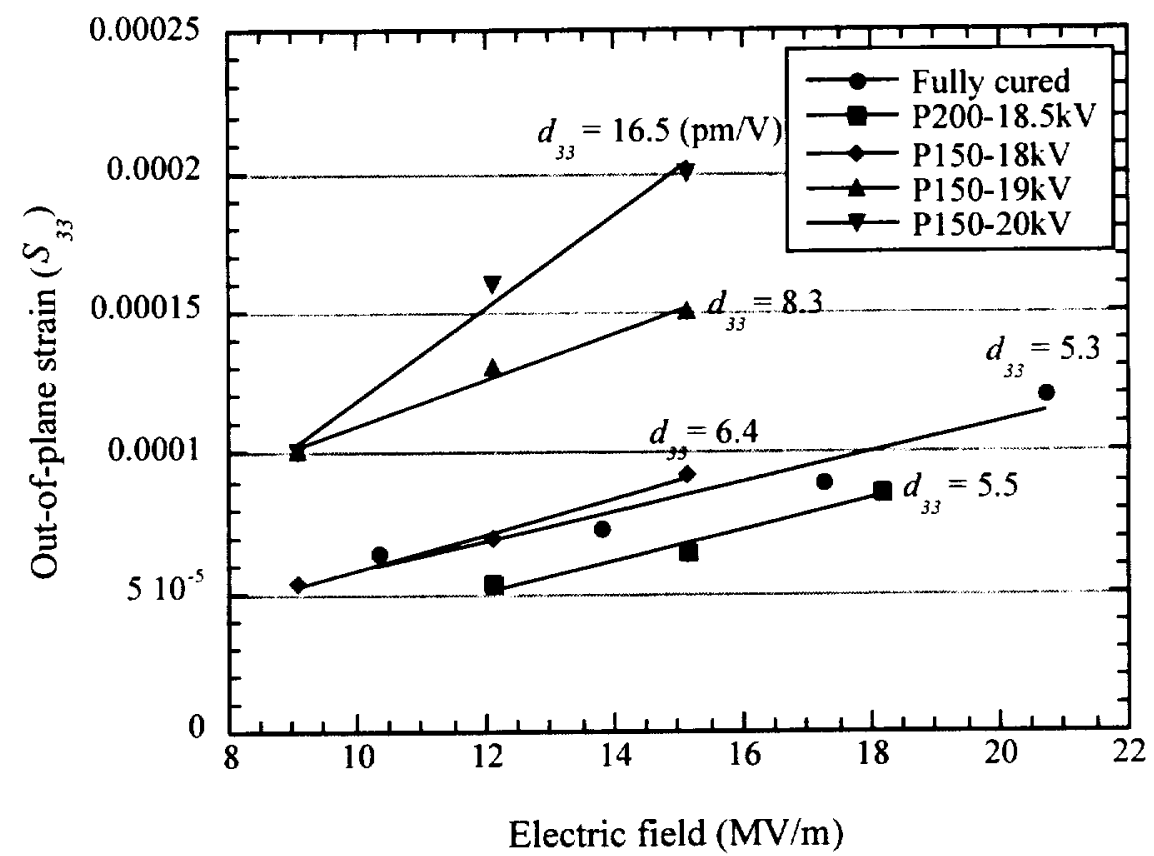

FIGURE 10. Out-of-plane strain as a function of the applied electric field: The piezoelectric strain coefficients $\left(d_{33}\right)$ are shown as the slopes.

3.5. Piezoelectric strain coefficient. The piezoelectric strain coefficients $\left(d_{33}\right)$ of the poled samples were calculated using Equation (4). This thickness strain (out-of-plane) was measured in response to the applied electric field. The strain $\left(S_{33}\right)$ increased linearly with the applied electric field for all the specimens regardless of the cure and poling cycles. This linear relationship confirms the piezoelectric nature of the amorphous polyimide response. It is obvious that P150 exhibits higher displacement characteristics, and hence, higher strains than the P200. Figure 10 shows the piezoelectric strain coefficient $\left(d_{33}\right)$ as a function of driving field. The conventionally poled P240 exhibited $d_{33}$ of 5.3 $\mathrm{pm} / \mathrm{V}$ and a similar value of $5.5 \mathrm{pm} / \mathrm{V}$ was obtained for the corona poled (at $18.5 \mathrm{kV}$ ) P200. The corona poled P150 showed a higher $d_{33}$ than the conventionally poled P240, and the piezoelectric coefficient increased with the poling field. When poled at $20 \mathrm{kV}$, the $d_{33}$ of the corona poled P150 was $16.5 \mathrm{pm} / \mathrm{V}$, which is three times higher than that of the conventionally poled P240. This value is about $43 \%$ of the value of PVDF, $38 \mathrm{pm} / \mathrm{V}$, which was prepared and measured by the same procedure for comparison. The piezoelectricity of PVDF, however, begins to decrease rapidly above $70^{\circ} \mathrm{C}$, while that of the $\mathrm{P} 150$ retains more than $90 \%$ of the initial value at room temperature after heating up to $150^{\circ} \mathrm{C}$ [11]. The thermal piezoelectric stability of this amorphous polyimide is potentially beneficial for use in micro-electromechanical systems (MEMS) devices and high temperature aerospace applications.

4. Conclusions. In situ poling and imidization of partially cured ( $\beta-\mathrm{CN}) \mathrm{APB} / \mathrm{ODPA}$ was studied in an attempt to maximize the degree of dipolar orientation and the resultant piezoelectricity. Monomer dipole moments in ( $\beta-\mathrm{CN}$ )APB/ODPA were studied using computational chemistry, which predicted that the dipole moment of a partially cured oriented amic acid (open imide ring) is four times higher than the fully imidized oriented closed ring. The partially cured, corona poled polymers exhibited higher dielectric relaxation strength $(\Delta \varepsilon)$, remanent polarization $\left(P_{r}\right)$ and piezoelectric strain coefficient $\left(d_{33}\right)$ than the fully cured, conventionally poled one, in agreement with the computational analysis. The piezoelectric strain coefficient of a polyimide prepared by the present method can be further increased by adding higher 
dipole concentration into the monomer unit. Therefore, this thermally stable polyimide may be an attractive alternative to PVDF for high temperature piezoelectric applications.

Acknowledgements. The authors thank Dr. Terry St. Clair for his technical insight and Dr. J. G. Smith, Jr. for his help in preparation of ( $\beta$-CN)APB/ODPA. NWChem Version 4.0.1, as developed and distributed by Pacific Northwest National Laboratory, P. O. Box 999, Richland, Washington 99352 USA, and funded by the U. S. Department of Energy, was used to obtain some of these results.

\section{REFERENCES}

[1] H. KaWAI, Jpn J Appl Phys, 8 (1969), p. 975.

[2] H.S. NAlWA, P.S. Viswanathan, AND P. VASUdEVAN, Angewante Makromol Chemie, 82 (1979), p. 39.

[3] S. Miyata, M. Yoshikawa, S. TASAKa, AND M. Ko, Piezoelectricity Revealed in the Copolymer of Vinylidene Cyanide and Vinyl Acetate, Polymer Journal, 12 (1980), p. 857.

[4] Y.S. JO, S. TASAKA, AND S. MrYATA, Piezoelectricity and Enthalpy Relaxation in the Copolymer of Vinylidene Cyanide and Vinyl Acetate, Sen-I Gakkaishi, 39 (1983), p. 451.

[5] T. Furukawa, M. Date, K. NAKaJIMA, T. KosakA, AND I. SEO, Large Dielectric Relaxations in an Alternate Copolymer of Vinylidene Cyanide and Vinyl Acetate, Japanese Journal of Applied Physics, 25 (1986), p. 1178.

[6] I. SEO, Ferroelectrics 171 (1995), p. 45.

[7] S. TASAKA, Cyanopolymers, in Ferrolectric Polymers, H.S. Nalwa ed., Marcel Dekker, Inc., New York, 1998, pp. 325-352.

[8] J.O. Simpson, S.S. WelCh, AND T.L. St. ClaIR, Novel Piezoelectric Polyimides, Proceeding of Materials Research Society Symposium: Materials for Smart Systems II, Boston, MA, Nov. 1996, volume 413, pp. 351-356.

[9] J.O. SIMPSON, Z. OUNAIES, AND C. FAY, Polarization and Piezoelectric Properties of a Nitrile Substituted Polyimide, Proceeding of Materials Research Society Symposium: Materials for Smart Systems II, Boston, MA, Nov. 1997, volume 459, pp. 59-64.

[10] Z. OUNAIES, C. PARK, J.S. HARRISON, J.G. SMITH, JR. AND J. HINKLEY, Structure-Property Study of Piezoelectricity in Polyimides, Proceeding of SPIE Smart Structures and Materials, Newport Beach, CA, Mar. 1999, volume 3669, pp. 171-178.

[11] C. PARK, Z. OUNAIES, J. SU, J.G. SMITH, JR. AND J.S. HARRISON, Polarization Stability of Amorphous Piezoelectric Polyimides, Proceeding of Materials Research Society Symposium:

Electroactive Polymers, Boston, MA, Nov. 1999, volume 600, pp. 153-158.

[12] K.E. WISE, Computational Chemistry, in Electroactive Polymers (EAP) Actuators as Artificial Muscles, Y. Bar-Cohen, ed., SPIE Press: Washington, 2001, Chapter 10, pp. 267-284.

[13] T. FURUKaWA, Piezoelectricity an Pyroelectricity in Polymers, Proceeding of 6th International IEEE Symposium on Electrets, 1988, pp. 182-193.

[14] C.A. PRYDE, IR Studies of Polyimides. I. Effects of Chemical and Physical Changes During Cure, Journal of Polymer Science: Part A: Polymer Chemistry, 27 (1989), p. 711.

[15] High PERFormanCE COMPUTATIONAL ChEMISTRY GROUP, NWChem, A Computational Chemistry Package for Parallel Computers, Version 4.0.1 (2001), Pacific Northwest National Laboratory, Richland, Washington 99352, USA. 
[16] A.D.BECKE, Density-Functional Thermochemistry. III. The Role of Exact Exchange, Journal of Chemical Physics, 98 (1993), p. 5648.

[17] P.C. HARIHARAN, AND J.A. POPLE, The Influence of Polarization Functions on Molecular Orbital Hydrogenation Energies, Theoretical Chemistry Acta, 28 (1973), p. 213.

[18] J. PONDER, ET.AL. Tinke 3.9, See http://dasher.wustl.edu/tinker/

[19] C.I. BAYLY, P. CIEPLAK, W.D. CORNELl, AND P.A. KOllMAN, A Well-Behaved Electrostatic Potential Based Method Using Charge Restraints for Determining Atom-Centered Charges: The RESP Model, Journal of Physical Chemistry, 97 (1993), p. 10269.

[20] N.L. Allinger, Y.H. YuH, AND J.-H. LiI, Molecular Mechanics. The MM3 Force Field for Hydrocarbons, Journal of American Chemical Society, 111 (1989), p. 8551.

[21] R. KUTTEH, RATTLE Recipe For General Holonomic Constraints: Angle And Torsion Constraints, CCP5 Newsletter, 46 (1998), p. 9. 


\begin{tabular}{|c|c|c|c|}
\hline \multicolumn{3}{|c|}{ REPORT DOCUMENTATION PAGE } & $\begin{array}{l}\text { Form Approved } \\
\text { OMB No. 0704-0188 }\end{array}$ \\
\hline \multicolumn{4}{|c|}{ 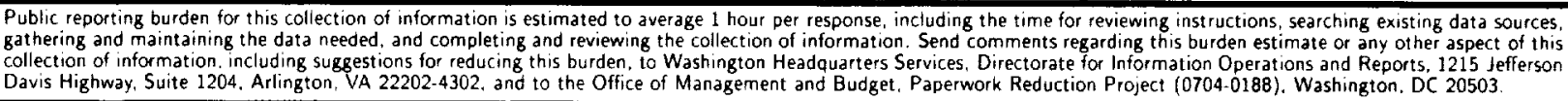 } \\
\hline 1. AGENCY USE ONLY(Leave blank) & $\begin{array}{l}\text { 2. REPORT DATE } \\
\text { October } 2002\end{array}$ & \multicolumn{2}{|c|}{$\begin{array}{l}\text { 3. REPORT TYPE AND DATES COVERED } \\
\text { Contractor Report }\end{array}$} \\
\hline \multicolumn{3}{|c|}{$\begin{array}{l}\text { 4. TITLE AND SUBTITLE } \\
\text { IN SITU POLING AND IMIDIZATION OF AMORPHOUS } \\
\text { PIEZOELECTRIC POLYIMIDES }\end{array}$} & \multirow[t]{2}{*}{$\begin{array}{l}\text { 5. FUNDING NUMBERS } \\
\text { C } \ \text { AS1-97046 } \\
\text { WL } 505-90-52-01\end{array}$} \\
\hline \multicolumn{3}{|c|}{$\begin{array}{l}\text { 6. AUTHOR(S) } \\
\text { Cheol Park, Zoubeida Ounaies, Kristopher E. Wise, and Joycelyn S. Harrison }\end{array}$} & \\
\hline \multicolumn{3}{|c|}{$\begin{array}{l}\text { 7. PERFORMING ORGANIZATION NAME(S) AND ADDRESS(ES) } \\
\text { ICASE } \\
\text { Mail Stop } 132 \mathrm{C} \\
\text { NASA Langley Research Center } \\
\text { Hainpton, VA } 23681-2199\end{array}$} & $\begin{array}{l}\text { RMING ORGANIZATION } \\
\text { T NUMBER } \\
\text { E Report No. } 2002-39\end{array}$ \\
\hline \multicolumn{3}{|c|}{$\begin{array}{l}\text { 9. SPONSORING/MONITORING AGENCY NAME(S) AND ADDRESS(ES) } \\
\text { National Aeronautics and Space Administration } \\
\text { Langley Research Center } \\
\text { Hampton, VA } 23681-2199\end{array}$} & $\begin{array}{l}\text { 10. SPONSORING/MONITORING } \\
\text { AGENCY REPORT NUMBER } \\
\text { NASA/CR-2002-211948 } \\
\text { ICASE Report No. } 2002-39\end{array}$ \\
\hline \multicolumn{4}{|c|}{$\begin{array}{l}\text { 11. SUPPLEMENTARY NOTES } \\
\text { Langley Technical Monitor: Dennis M. Bushnell } \\
\text { Final Report } \\
\text { To be submitted to the Journal of Polymer Science: Polymer Physics B. }\end{array}$} \\
\hline \multicolumn{2}{|c|}{$\begin{array}{l}\text { 12a. DISTRIBUTION/AVAILABILITY STATEMENT } \\
\text { Unclassified-Lnlimited } \\
\text { Subject Category } 34 \\
\text { Distribution: Nonstandard } \\
\text { Availability: NASA-CASI (301) 621-0390 }\end{array}$} & & 12b. DISTRIBUTION CODE \\
\hline \multicolumn{4}{|c|}{$\begin{array}{l}\text { 13. ABSTRACT (Maximum } 200 \text { words) } \\
\text { An amorphous piezoelectric polyimide containing polar functional groups has been developed using a combination of } \\
\text { experimental and molecular modeling for potential use in high temperature applications. This amorphous polyimide, } \\
\text { ( } 3-\mathrm{CN}) \mathrm{APB} / \text { ODPA, has exhibited good thermal stability and piezoelectric response at temperatures up to } 150 \mathrm{C} \text {. } \\
\text { Density functional calculations predicted that a partially cured amic acid (open imide ring) possesses a dipole } \\
\text { moment four times larger than the fully imidized closed ring. In situ poling and imidization of the partially cured } \\
\text { ( } 3 \text {-CN)APB/ODPA was studied in an attempt to maximize the degree of dipolar orientation and the resultant } \\
\text { piezoelectric response. A positive corona poling was used to minimize localized arcing during poling and to allow use } \\
\text { of higher poling fields without dielectric breakdown. The dielectric relaxation strength, remanent polarization, and } \\
\text { piezoelectric response were evaluated as a function of the poling profile. The partially cured, corona poled polymers } \\
\text { exhibited higher dielectric relaxation strength (delta varepsilon), remanent polarization }\left(P_{r}\right) \text { and piezoelectric strain } \\
\text { coefficient }\left(d_{33}\right) \text { than the fully cured, conventionally poled ones. }\end{array}$} \\
\hline \multirow{2}{*}{\multicolumn{3}{|c|}{$\begin{array}{l}\text { 14. SUBJECT TERMS } \\
\text { in situ poling, amorphous polyimide, piezoelectricity, polarization, modeling }\end{array}$}} & $\begin{array}{l}\text { 15. NUMBER OF PAGES } \\
20\end{array}$ \\
\hline & & & $\begin{array}{c}\text { 16. PRICE CODE } \\
\mathrm{A} 03\end{array}$ \\
\hline $\begin{array}{l}\text { 17. SECURITY CLASSIFICATION } \\
\text { OF REPORT } \\
\text { Unclassified }\end{array}$ & $\begin{array}{l}\text { 18. SECURITY CLASSIFICATION } \\
\text { OF THIS PAGE } \\
\text { Unclassified }\end{array}$ & $\begin{array}{l}\text { 19. SECURITY CLASSIFICATION } \\
\text { OF ABSTRACT }\end{array}$ & $\begin{array}{l}\text { 20. LIMITATION } \\
\text { OF ABSTRACT }\end{array}$ \\
\hline NSN 7540-01-280-5500 & & & $\begin{array}{l}\text { Standard form } 298(\text { Rev. 2-89) } \\
\text { Prescribed by ANSI Std. Z39. } 18 \\
298.102\end{array}$ \\
\hline
\end{tabular}

